\title{
XLVIII. On the scale-value of the late Dr. Joule's thermometers
}

\author{
Arthur Schuster F.R.S.
}

To cite this article: Arthur Schuster F.R.S. (1895) XLVIII. On the scale-value of the late Dr. Joule's thermometers, Philosophical Magazine Series 5, 39:241, 477-501, DOI:

10.1080/14786449508620747

To link to this article: http://dx.doi.org/10.1080/14786449508620747

曲 Published online: 08 May 2009.

Submit your article to this journal $[\pi$

Џ Article views: 3

Q View related articles $\asymp$ 
LONDON, EDINBURGH, AND DUBLIN

\title{
PHILOSOPHICAL MAGAZINE
}

\author{
AND \\ JOURNAI OF SCIENCE.
}

[FIFTH SERIES.]

$J U N E 1895$.

XLVIII. On the Scale-Value of the late Dr. Joule's Thermometers. By ARTHUR SchUSTRR, F.R.S.**

[Plates V. \& VI.]

TN order to bring the results of Joule's researches on the mechanical equivalent of heat into relation with more modern experiments on the same subject, it is necessary to determine the scale-value of Joule's thermometers in terms of some easily reproducible standard.

We possess already a comparison by Joule himself of his thermometer with one used by Rowland, who has corrected Joule's result to the scale of his own air-thermometer.

Some doubt may still exist, however, as to the true scalevalue of these instruments, partly owing to the fact that we have no information how the comparison between Joule's and Rowland's thermometers was conducted, and partly because we do not know to what degree of accuracy Rowland's airthermometer would agree with that of the Bureau International des Poids et Mesures, which for the present must be considered as the standard.

The historical importance of the instruments used by Joule seemed to make it desirable therefore to subject them to a more extended investigation. The request which I made to $\mathrm{Mr}$. B. A. Joule to allow me the use for a short time of his late father's thermometers was met by a most ready complianee,

* Communicated by the Author.

Phil. Mag. S. 5. Vol, 39. No. 241. June 1895. $2 \mathrm{~K}$ 
and I beg to offer him my best thanks for the opportunity which he has given me of examining these interesting relics.

The two thermometer's which I had at my disposal were those called A and D in Jonle's published papers ; they were made and calibrated by Dancer in 1844. The thermometer $\mathrm{D}$ includes both the freezing- and boiling-point, while A only reaches to a little above $30^{\circ} \mathrm{C}$.

In order to show to what extent Joule trusted these instruments; I quote the passages in his papers in which he refers to them :-

"My thermometers were constructed by a method very similar to that employed by Regnault and Pierre. The calibre of the tube was first measured in every part by passing a short column of mereury along it. The surface of the glass having then been covered with a thin film of beeswax, the portions of tube previously measured were each divided into the same number of parts by a machine constructed for the purpose. The divisions were then etched by means of the vapour of fluoric acid. Two thermometers were employed in the present research, in one of which the value of each space was $\frac{1}{18 \cdot 14}$, in the other $\frac{1}{23 \cdot 38}$ of a degree Centigrade. A practised eye can easily estimate the tenth part of each of these spaces ; consequently I could by these thermometers observe a difference of temperature not greater than $0^{\circ}$ 005." (Phil. Mag. [4] vol. iii. p. 481 ; Collected Works, vol. i. p. 214.)

"The thermometers employed had their tubes calibrated and graduated according to the method first indicated by Regnault. 'Two of them, which I shall designate by $A$ and $B$, were constructed by Mr. Dancer of Manchester ; the third, designated by $\mathrm{C}$, was made by $M$. Fastre of Paris. The graduation of these instruments was so correct, that when compared together their indications coincided to about $\frac{1}{100}$ of a degree Fahr. I also possessed another exact instrument made by Mr. Dancer, the scale of which embraced both the freezing- and boiling-points. The latter point in this standard thermometer was obtained, in the usual manner, by immersing the bulb and stem in the steam arising from a considerable. quantity of pure water in rapid ebullition. During the trial the barometer stood at $2 \% 94$ inches, and the temperature of the air was $50^{\circ}$, so that the observed point required very little correction to reduce it to 0.760 metre and $0^{\circ} \mathrm{C}$, the pressure used in France, and J. believe the Continent generally, for determining the boiling-point, and which has been employed by me on account of the number of accurate thermometrical 
researches which have been constructed on that basis. The values of the scales of the thermometers $A$ and $B$ were ascertained by plunging them along with the standard in large volumes of water kept constantly at various temperatures. The value of the scales of thermometer $\mathrm{C}$ was determined by comparison with $A$. It was thus found that the number of divisions corresponding to $1^{\circ} \mathrm{Fahr}$. in the thermometers $\mathrm{A}$, $B$, and $C$ were $12 \cdot 951,9 \cdot 829$, and $11 \cdot 647$ respectively. And since constant practice had enabled me to read off with the naked eye to $\frac{1}{20}$ of a division, it followed that $\frac{1}{2} \frac{1}{00}$ of a degree Fahr. vas an appreciable temperature." (Phil. Trans. 1850, pt. i.; Collected Works, vol. i. p. 302.)

On the Centigrade scale the figures given in the last quotation would be $23 \cdot 312,17 \cdot 692,20 \cdot 965$. This allows us to identify the second thermometer of the first quotation with the one called $\mathrm{A}$ in all subsequent papers.

"The thermometer used to indicate the temperature of the calorimeter was the same which I employed in my former experiments. Those designated $A$ and $D$ were calibrated with great care. I have recently compared them together at 50 different temperatures between $32^{\circ}$ and $80^{\circ}$ Fahr., the result being that, if the less sensitive was assumed to be correct, the other, or $A$, nowhere appeared more than $0^{\circ} .023$ in error; bnt taking averages for each consecutive $10^{\circ}$, this error amounted to no more than $0^{\circ} .008 . "$ (Phil. Trans. 1878, part ii.; Collected Works, vol. i. p. 636.)

\section{Description of the Thermometer's.}

The two thermometers which $I$ had at my disposal were those called A and D. The form and size of their bulb and the width of the stem are shown in figs. 1 and 2 , the former representing in natural size the bulb and beginning of the stem of the thermometer $A$, and the latter that of $D$. The diameters of the two stems are 0.7 centim. (A) and 0.75 centim. (D). The length of the stems 87 centim. (A) and 86 centim. (D). The volumes of the bulbs may be calculated approximately from their shape, and are found to be $4 \cdot y$ cub. centim. and $3 \cdot 8$ cub. centim. respectively.

As the thermometer A was the one always employed in calorimetric measurements, it is this instrument which is of chief interest to us now. From the pressure coefficients of the thermometer, we may approximately calculate the thickness of the glass walls of the bulb, in the manner indicated by Guillaume. The calculation can be carried out if the bulb is aylindrical or spherical, and cannot strictly be applied to such 
a shape as that shown in fig. 1. But I find that, assuming the bulb to be cylindrical, the pressure-coefficient gives a

Fig: 1.

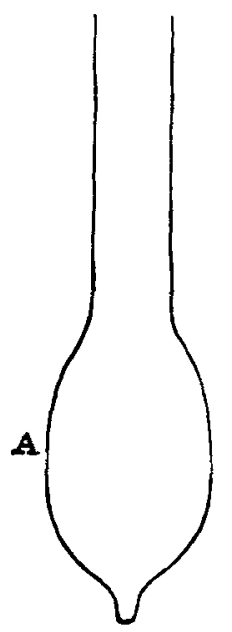

Fig. 2.

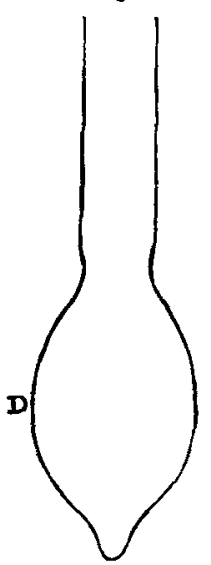

thickness of $0.09 *$, while on the assumption that it is spherical the calculated thickness of glass is 0.076 , so that the result is almost the same, and we are not probably far wrong in taking .08 as the approximate thickness. Taking account of this value and the external volume, I find the volume of mercury to be about 4 cub. centim., and from the length of one degree of the stem obtain the radius of the bore approximately as -009. These numbers do not lay claim to any aceuracy, but they are sufficient to give us an idea of the principal quantities involved in the construction of this thermometer.

As the thermometer was calibrated before graduation, the distance between the divisions will give us some idea as to the regularity of the bore. In Table 1 . the first column gives the division of the thermometer, and the second, in millimetres, the corresponding distance from the centre of the reservoir, the third column gives the differences between the numbers of the second, and the numbers of this column are therefore inversely proportional to the mean area of the bore at different points of the thermometer.

* All resulte, unless otherwise stated, are given in centims. 
Table I.

\begin{tabular}{|c|c|c|c|}
\hline Division. & $\begin{array}{l}\text { Distance from } \\
\text { centre of bulb. }\end{array}$ & $\begin{array}{c}\text { Distance between } \\
\text { successire intervals } \\
\text { of } 50 \text { divisions. }\end{array}$ & $\begin{array}{l}\text { Pressure } \\
\text { correction in } \\
\text { degrees. }\end{array}$ \\
\hline $\begin{array}{l}0 \\
23 \cdot 3 \text { (zero) } \\
50 \\
100 \\
150 \\
200 \\
250 \\
300 \\
350 \\
400 \\
450 \\
500 \\
550 \\
600 \\
650 \\
700 \\
750\end{array}$ & $\begin{array}{r}9 \cdot 2 \\
11 \cdot 1 \\
13 \cdot 4 \\
17 \cdot 7 \\
22 \cdot 2 \\
26 \cdot 7 \\
31 \cdot 4 \\
36 \cdot 1 \\
40 \cdot 8 \\
45 \cdot 6 \\
50 \cdot 6 \\
55 \cdot 7 \\
60 \cdot 9 \\
66 \cdot 0 \\
71 \cdot 2 \\
76 \cdot 5 \\
81 \cdot 8\end{array}$ & $\begin{array}{c}\ldots \ldots . \\
\ldots \ldots . . \\
4 \cdot 2 \\
4 \cdot 3 \\
4 \cdot 5 \\
4 \cdot 5 \\
4 \cdot 7 \\
4 \cdot 7 \\
4 \cdot 7 \\
4 \cdot 8 \\
5 \cdot 0 \\
5 \cdot 1 \\
5 \cdot 2 \\
5 \cdot 1 \\
5 \cdot 2 \\
5 \cdot 3 \\
5 \cdot 3\end{array}$ & $\begin{array}{r}0.0234 \\
.0284 \\
.0343 \\
.0453 \\
.0567 \\
.0683 \\
.0802 \\
.0922 \\
.1042 \\
.1165 \\
.1292 \\
.1423 \\
.1556 \\
.1686 \\
.1819 \\
.1955 \\
.2089\end{array}$ \\
\hline
\end{tabular}

To calculate the pressure correction we require the distances from the centre of the bulb, but there must of course be some uncertainty as to the point which is chosen as centre. The figures in the third column were obtained by direct measurement and are not affected by the same uncertainty. It will be seen that the bore is conical, gradually diminishing in diameter. The mean cross-sections near the two ends of the tube differ by about 20 per cent.

In addition to the differences in the length of division intended to correct for the changes in the bore, there are also not inconsiderable inequalities which are evidently due to faults of graduation. These irregularities are quite visible with the naked eye, two successive intervals differing occasionally by as much as the tenth part of their own length. Owing to this fact the error of a single reading of this thermometer A may amount to $0^{\circ} .004 \mathrm{C}$. quite independently of the general errors of calibration. It must be remembered of course that at the time the thermometers were made such a quantity was not considered to be of any importance, so that the divisions were sufficiently accurate for the purposes for which they were originally intended. 


\section{The Fundamental Points.}

As regards the thermometer $D$, Joule has supplied us with the following information:-

"The freezing-point of the standard D had risen from 13.3 divisions of its scale in 1844 to 15.14 in 1877 . I think it probable that the boiling-point of this thermometer, if kept constantly at this temperature, would in the course of time fall as much. The five careful determinations of this boilingpoint referred to $30 \mathrm{bar}$. and $60^{\circ}$ are respectively $706,706^{\circ} 4$, $706,705.9$, and 706.15 -mean 706.09 . Subtracting 1.84 , $704 \cdot 25$ will be the probable ultimate reading, from which if we take 15.14 we shall have $689 \cdot 11$ as the range between the fixed points cleared from the effects of imperfect elasticity of the glass. Mr. E. Hodgkinson has pointed out (Brit. Assoc. Report, 1843, p. 23) that the 'set' of imperfectly elastic bodies is proportional to the square of the force applied, therefore the effect of imperfect elasticity in the glass of the thermometers will be insensible for the small ranges used in the experiments, and the factor 3.3822 for reducing the indications of $D$ to those of $A$ may be confidently relied on.

"We have therefore

$$
\frac{180}{684 \cdot 11 \times 3.3822}=0^{\circ} \cdot 07723
$$

as the most probable value of one division of $A$. In my former papers the number was taken as $0^{\circ} .077214$, which is so near that I shall continue to use it, trusting by longcontinued observations of the fixed points to give it ultimately greater accuracy, and also, by experiments above indicated, to state it in terms of the absolute interval between these points." (Phil. Trans. 1878, part ii.; Collected Works, vol.i. p. 636.)

It will be noticed that the actually observed difference between the freezing- and boiling-point is 690.95 divisions, but that Joule somewhat arbitrarily reduced this by 1.84 divisions, thus altering the fundamental interval by over a quarter per cent. It seems curious that no one should have directed his attention to this point, which to all appearance causes an error in the scale-value of his thermometer, and would make his equivalent come out too low by ${ }^{\circ} 0027$ of its own value.

If we collect together the scale-values of the thermometer A, given by Joule in different places, we find :- 


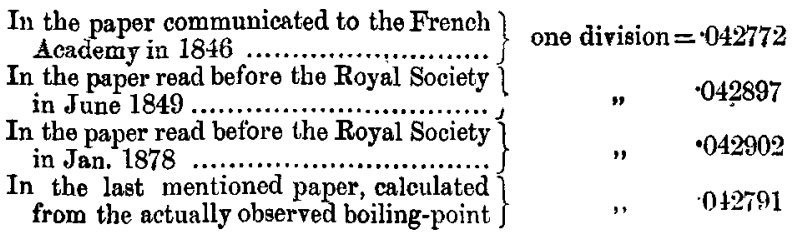

It will be seen that the last value nearly agrees with the first; the point to be explained therefore is the high value of the second number. It is possible that a correction similar to that of the last paper was already then applied, and as we have reason to believe that a great part of the change of zero took place in the first four years, we may account for certainly half the difference in this way. The point is not now of great importance, because the scale-value of A must be obtained quite independently of Joule's assumed interval for his standard. Joule's own value depended not only on that interval but also on the correct calibration of his standard. From the method of calibration employed, an error quite as large as that caused by the wrong valne of the boiling-point might easily be introduced. Nevertheless a re-determination of the distance between boiling- and freezing-points seemed to me to be of interest, especially as the depression of the zero might give some indication as to the nature of the glass of which the thermometer is made.

When the thermometer came into my possession there was a large bubble of air in the bulb, and the mercury in the stem broke into pieces when attempts were made to drive the bubble into the upper reservoir. I finally succeeded, however, in removing it, but the experiments on the boiling-point were always a little difficult as the mercury when placed in steam had a great tendency to distil into the upper parts of the stem. In order to see that the thread was continuous the thermometer had to be inverted occasionally, the mercury running into the reservoir, and small pellets sometimes remained there on re-inverting, so that no value is to be attached to the actual position of the zero poinis observed; though the quantity of mercury separated was always so small that the distance between the freezing- and boiling-points could not be affected. Table II. gives the observations made:- 
Table II.

\begin{tabular}{|c|c|c|c|c|c|c|}
\hline \multirow{2}{*}{ Date. } & \multirow{2}{*}{$\begin{array}{l}\text { Height } \\
\text { of Baro- } \\
\text { meter. }\end{array}$} & \multirow{2}{*}{$\begin{array}{l}\text { Freezing- } \\
\text { point be- } \\
\text { fore ex- } \\
\text { periment. }\end{array}$} & \multirow{2}{*}{$\begin{array}{l}\text { Freezing- } \\
\text { point after } \\
\text { experi- } \\
\text { ment. }\end{array}$} & \multicolumn{2}{|c|}{ Interval. } & \multirow{2}{*}{$\begin{array}{c}\text { Depres- } \\
\text { sion of } \\
\text { zero. }\end{array}$} \\
\hline & & & & $a_{\text {. }}$ & $b$. & \\
\hline April 7,1892 . & $759 \cdot 1$ & $15 \cdot 04$ & $14 \cdot 3 \overline{5}$ & $690 \cdot 79$ & $691 \cdot 48$ & 69 \\
\hline May $11, \quad "$ & $769 \cdot 1$ & 1658 & 16.04 & $689 \cdot 63$ & 69017 & 54 \\
\hline May 30, ", & $759 \cdot 7$ & $4 \cdot 97$ & $4 \cdot 46$ & $690 \cdot 97$ & $691 \cdot 48$ & $\cdot 51$ \\
\hline June 22, 1894. & $766^{\circ} 0$ & $9 \cdot 88$ & 9.08 & $690 \cdot 69$ & 691.49 & 80 \\
\hline \multicolumn{6}{|c|}{ Mean......... } & 64 \\
\hline
\end{tabular}

The agreement between the experiments, excepting the second, is better than could have been expected, and accident must have played some part in giving these practically identical numbers. The first and third determinations were made by myself, the fourth by Mr. J. R. Ashworth, the second by another observer, and there must be some error in it which could not afterwards be traced. The intervals are given in 2 columns- $(a)$ is the interval calculated on the old method of taking the freezing-point first, while $(b)$ is that now generally employed, the reading at the boiling-point being compared with the reading at the freezing-point taken immediately afterwards. The difference between the number so obtained and Joule's interval (690.95) gives the depression of zero as 53 , agreeing fairly well with that found directly by the above experiments. The interval $(a)$ is also seen to agree with Joule's value. The time the thermometer was kept exposed to the temperature of boiling water varied from a quarter of an hour to several hours. In the first three experiments the depression seemed to increase with the time of exposure, but in the last experiment that time was only about fifteen minutes, i.e. shorter than in the other cases ; the large depression may be due to a diminution of the column by distillation.

It appears, therefore, that the depression of the zero is less than $0^{c} 1$. It approaches that observed in Jena or French hard-glass thermometers, and is considerably smaller than that found with modern English glass.

The Tlitrmometer A.-This thernometer does not include the boiling-point, but its freezing-point is of interest, as it is 
probably unique in having keen watched for a period of over 50 years. Joule furnishes us with data showing the gradual rise of the zero from April 1844 to March 4, 1873 (Collected Works, vol. i. p. 558). In the communication he presented to the Manchester Literary and Philosopbical Society, he refers the rise to the first observed zero without giving the actual readings, so that this short paper dces not allow us to judge how far the present zero is above that of 1873 . Fortunately, we can indirectly supply the deficiency. For in his comparison with Rowland's thermometer (Proc. Amer. Acad. vol. xvi. p. 38) the reading of the zero is stated to be $22 \cdot 62$. Rowland's thermometer was sent to Joule in the summer of 1879 , and the results were communicated to the American Academy in March 1880. The comparison must bave been made at an intermediate date, and can therefore be identified, for in the above-mentioned communication only one comparison is mentioned between January 1877 and December 1882 , and that one in November 1879 , when the zero stood $12 \cdot 92$ divisions above that of the first observation. Taking the original zero to be $9 \cdot 7$, the complete series now is as follows :-

TABLE III.

\begin{tabular}{|c|c|c|c|}
\hline Date. & Zero. & Date. & Zero. \\
\hline $\begin{array}{l}\text { April } 1844 \\
\text { February } 18 . \ldots . . \\
\text { January } 1848 \quad \ldots \\
\text { April } 1848 \\
\text { February } \\
1853 . . .\end{array}$ & $\begin{array}{r}9 \cdot 7 \\
152 \\
16 \cdot 3 \\
16 \cdot 6 \\
18.5\end{array}$ & $\begin{array}{l}\text { February } 1873 . . \\
\text { January } 1877 . \\
\text { November } 1879 . \\
\text { December } 1882 .\end{array}$ & $\begin{array}{l}-2 \cdot 2 \\
22 \cdot 41 \\
22 \cdot 62 \\
2296\end{array}$ \\
\hline $\begin{array}{l}\text { April } 1856 \\
\text { December } \\
\text { March } 1860 . . \\
\text { February } 187 \ldots \ldots \\
1870 \ldots\end{array}$ & $\begin{array}{l}19 \cdot 2 \\
20.8 \\
21 \cdot 5 \\
21 \cdot 8\end{array}$ & $\begin{array}{l}\text { April } 1892 \ldots \ldots . \\
\text { April } 1893 \ldots \ldots . \\
\text { June } 1894 \ldots \ldots\end{array}$ & $\begin{array}{l}23 \cdot 36\left(17^{\circ}\right) \\
23 \cdot 31\left(17^{\circ} \cdot 6\right) \\
23 \cdot 35\left(17^{\circ}\right)\end{array}$ \\
\hline
\end{tabular}

I have taken a considerable number of readings of the zero-point since the beginning of the year 1892. They vary of course with the temperature to which the thermometer was exposed. The determinations were made in an apparatus similar to that described by Guillaume, the thermometer being immersed in a mixture of scraped ice and distilled water. Great care must be exercised in the readings, for, owing to the large size of the bulb and the long time taken by the thermometer to reach a steady state, the results are easily vitiated by an accumulation of water. No correction was made for the pressure due to the surrounding mixture, as probably Joule took no account of that pressure, nor would the correction be significant for our purpose. The readings are arranged in 
groups according to the temperature at which the thermometer had been kept, and I have divided them into three periods.

\begin{tabular}{|c|c|c|}
\hline \multicolumn{3}{|c|}{$\begin{array}{l}\text { First Period. } \\
\text { March } 30 \text { to April 7, } 1892 .\end{array}$} \\
\hline $\begin{array}{l}\text { A verage temperature to } \\
\text { which the thermometer } \\
\text { had beea exposed. }\end{array}$ & $\begin{array}{l}\text { Number of } \\
\text { Observations. }\end{array}$ & Mean zero \\
\hline $8 \cdot 6$ & 2 & $23 \cdot 47$ \\
\hline $12 \cdot 9$ & 4 & $23 \cdot 41$ \\
\hline $17 \cdot 1$ & 2 & $23 \cdot 36$ \\
\hline $30 \cdot 9$ & 1 & $23 \cdot 05$ \\
\hline
\end{tabular}

Second Period.

0

$13 \cdot 7$

$17 \cdot 6$

$23 \cdot 3$

17
March to June 1893.

1

3

3
$23 \cdot 31$

$23 \cdot 32$

Thir d Period.

June 22, 1894.

The first observation of the second series does not fit in very well with the others, but if it is remembered that a tenth part of a division means only $0^{\circ} \cdot 004$, the general agreement must be considered satisfactory, and the first series, which is perhaps the one in which the greatest care was exercised, shows the gradual lowering of the freezing-point very decidedly. The numbers show that the changes of zero are no longer appreciable. I have added to Table III. those of my observations which were taken after the thermometer had been exposed to about $17^{\circ}$.

\section{The Pressure Correction.}

As the chief object of this investigation was to find the scale-value of the thermometer $A$ under the conditions holding in Joule's experiment, the most natural manner of proceeding would have been to compare it in the vertical position with some standard instrument. Owing to the great length of the thermometer it was not found possible, however, without much inconvenience to construct a vessel into which it could entirely be plunged vertically, and if only partially immersed the uncertain stem corrections would take away 
considerably from the accuracy of the comparison. After a few trials which gave no satisfactory results, it was resolved to carry out the comparisons in a horizontal position and to determine independently the correction which has to be applied in order to reduce the readings to the vertical. This correction owes its origin to the expansion of the thermometerbulb throngh the internal pressure of the mercury column. It is determined by measuring the effect of external pressure. If the addition of an external pressure $p$ produces a rise of the column of mercury equal to $p \beta_{\epsilon}$ degrees, and an equal internal pressure produces a fall $p \beta_{i}$, then two equal pressures $p$ applied from both sides would produce a rise equal to $p\left(\beta_{\varepsilon}-\beta_{i}\right)$, but this rise may be calculated in another way. $\mathrm{A}$ hydrostatic pressure $p$ will alter the volume of the vessel by $p \kappa_{g}^{\prime}$, but the apparent contents of the ressel as measured by the mercury thread will only diminish by $p\left(\kappa_{g}-\kappa_{m}\right)$ where $\kappa_{g}$ and $\boldsymbol{\kappa}_{m}$ are the coefficients of cubical compression of glass and mercury respectively.

We thns obtain the equation

$$
\begin{aligned}
\beta_{i} & =\beta_{\varepsilon}+\left(\kappa_{m}-\kappa_{g}\right) \\
& =\beta_{\mathrm{\varepsilon}}+0.000154 \frac{\text { degrees }}{\text { centim. of mercury }} *
\end{aligned}
$$

This equation is deduced by Guillaume for the case of thermometers with cylindrical bulbs, but, as is shown by the preceding deduction, it holds quite generally.

The apparatus used for the determination of the pressure corrections is shown in Pl. V. fig. 3, and, as will be seen, is almost identical with that described in Guillaume's book. The thermometer is suspended in a long glass tube $\mathrm{T}$, into which sufficient mercury is introduced to cover the bulb; the rest of the tube is filled with glycerine in order to reduce the air-space as much as possible. Side tubes, with stop-cocks $A$ and $B$, are led into the upper end of $T$-one communicates with the outer air, the other with a pressure-gauge, a Winchester quart vessel $K$, and a water-pump. If the cocks $A$ and $B$ are closed and the pump set to work, it will gradually exhaust the vessel $K$, and when the pressure is sufficiently reduced $B$ is suddenly opened. Owing to the large volume of $\mathrm{K}$, compared to the air-space in $\mathrm{T}$, the pressure-gange remains sensibly unaltered, and the reduction of pressure can at once be observed on the thermometer, which is read off by a kathetometer telescope. The pressure can be restored to the atmospheric pressure by closing B and opening $A$.

* Guillaume, Thermometrie, p. 103. 
Phil.Mag. S. 5. Vol. 39. P1.V.

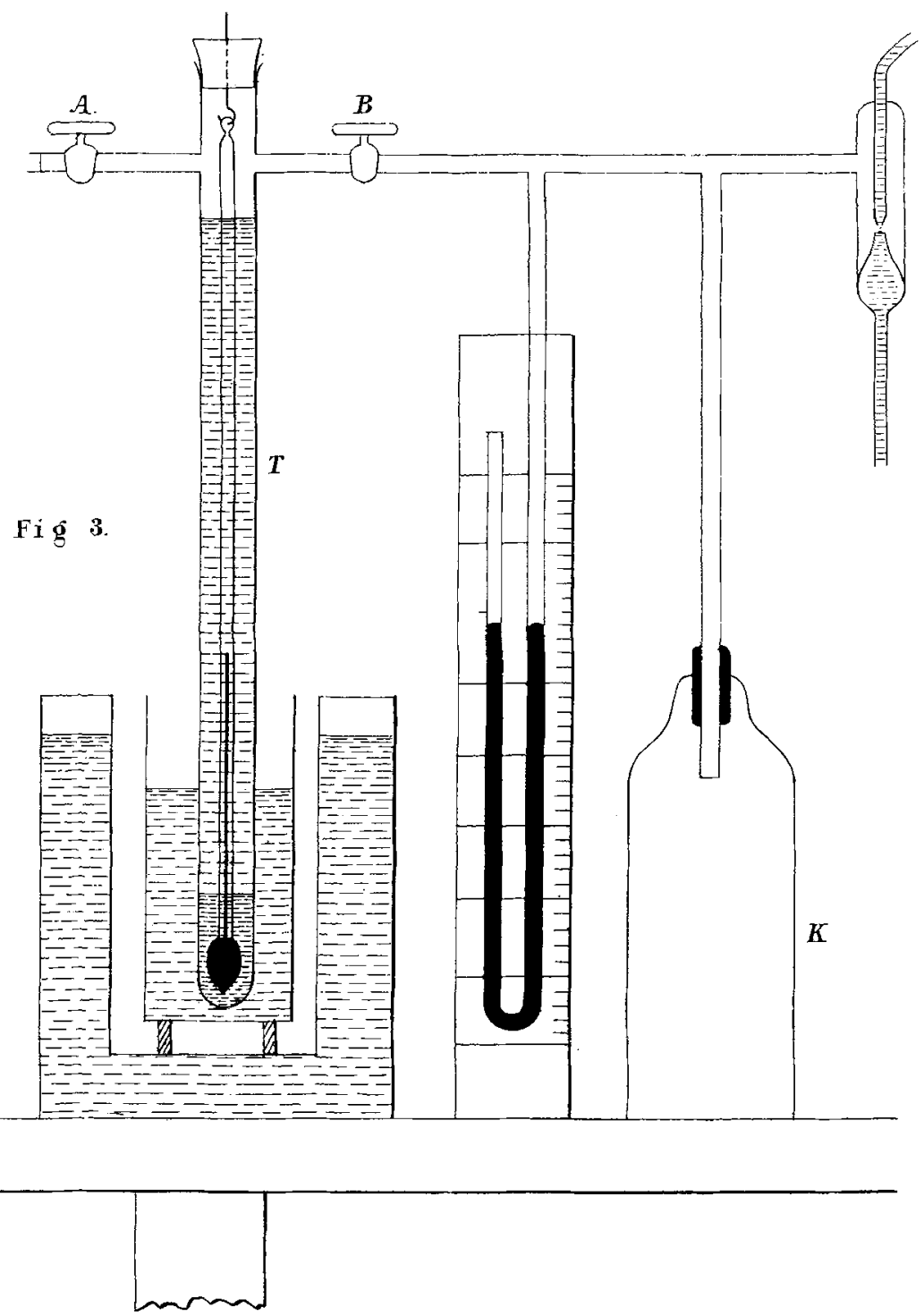


$I$ have found it convenient to proceed in the observations rather differently from the manner indicated by Guillaume. The tube $\mathrm{T}$ is placed in a calorimeter containing about a litre and a half of water, and that again is surrounded in an outer jacket. The latter is filled with water about $2^{\circ}$ above that in the calorimeter, so that the thermometer is kept slowly rising. The air-space in $T$ being exhausted, a few observations are taken at measured interrals of time, air is suddenly admitted, and a further series of readings are taken, as in the following example :-

\begin{tabular}{|c|c|c|c|}
\hline Observation. & Time. & Reading. & $\begin{array}{c}\text { Reading } \\
\text { Pressure Gauge. }\end{array}$ \\
\hline 1. & $\mathrm{~h}$ m & $158 \cdot 85$ & $72 \cdot 6$ \\
\hline 2. & 2.5 & $158 \cdot 85$ & \\
3. & 16 & 159.05 & \\
4. & 17.5 & $159 \cdot 17$ & \\
5. & $17 \cdot 5$ & $159 \cdot 30$ & \\
6. & 18 & $159 \cdot 35$ & \\
7. & $18 \cdot 5$ & $159 \cdot 40$ & \\
8. & 19 & $163 \cdot 60$ & \\
9. & $19 \cdot 5$ & $163 \cdot 70$ & \\
10. & 20 & $163 \cdot 75$ & \\
13. & $20 \cdot 5$ & $163 \cdot 85$ & \\
12. & 21 & $163 \cdot 95$ & \\
13. & $21 \cdot 5$ & $164 \cdot 05$ & \\
14. & 22 & $164 \cdot 20$ & \\
\hline
\end{tabular}

Taking the arithmetical mean between the first seven ob-. servations, it is found that the average temperature corresponding to the time $17^{\mathrm{m}}$ was $159 \cdot 139$, and by combining the observations in pairs in the usual fashion we deduce the average rate of rise per interval as $\cdot 108$. Hence

$$
159 \cdot 139+4 \times 10 \cdot 8=159 \cdot 571
$$

gives the calculated reading at $2^{\mathrm{h}} 19^{\mathrm{m}}$, but after the seventh reading the air was admitted, so that the last seven observations were taken at full atmospheric pressure. The reduction being made in exactly the same fashion, another reading is deduced for the time $2^{\mathrm{h}} 19^{\mathrm{m}}$, viz., 163.583 . The difference betwen the two gave 4.012 divisions of the thermometer as the effect of a change of pressure of $72 \cdot 6$ centim. A number of observations of a similar character were taken and are collected in Table IV. They were always so combined that the observation at aimospheric pressure followed that at reduced pressure. Otherwise a fall of the thermometer 
would have taken place, and owing to the sticking of the thread the first few observations would have been uncertain.

TaBle IV.

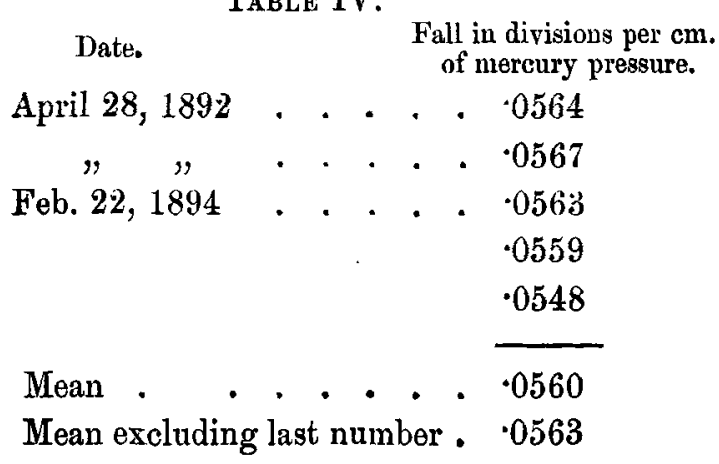

The observation which is quoted in full above is the one which shows greater irregularities in the rise than the others, and it gave the result (-0548) which differs most from the mean. Part of the discrepancies between the different observations is no doubt due to the irregularities in the graduation of this thermometer, but the result is sufficiently accurate for the purpose for which it is intended.

Reduced to degrees, the final results are as follows :-

$$
\begin{aligned}
& \text { In degrees per } \mathrm{cm} \text {. } \\
& \text { of mercury. } \\
& \text { Coefficient of external pressure . . . . 0.002400 } \\
& " \text { internal } " . . .90002554
\end{aligned}
$$

Knowing the distance of any scale-division from the centre of the reservoir, we may calculate the corresponding pressure correction. A table was calculated once for all, giving in this way the ditferences between the readings of the thermometer in the horizontal and vertical positions for every 50 divisions. The numbers are given in the last column of Table I. It will be noticed that an error of 1 per cent. in the pressure correction would cause a difference of less than $0^{\circ} .002$ un a range of over $30^{\circ}$, which difference of course would be quite inappreciable.

Some experiments were made to find how much the thermometer A lagged behind when placed in water the temperature of which was uniformly rising. They were carried out according to the manner described by Thiesen*, and gave sufficiently consistent results showing the time constant to be $12^{\circ}$.

$$
\text { * Guillaume, Thermomitrie, p. } 187 .
$$


The Apparatus used in the Comparison of Thermometers.

The comparison of the thermometers was carried out in a bath made of sheet-iron having a length of 114 centim. and width and depth of 20 centim. This bath was placed for protection inside a wooden box, on the bottom of which it rested upon two ribs covered with guttapercha, so that the inner vessel was practically insulated thermally. The wooden box $K$ is shown in Pl. VI. fig. 4, placed on two stools and in front of a table T. A frame FF fitted into the bottom of the bath and carried 38 turns of No. 21 nickel wire, the ends of the wire being brought to binding-screws placed at two of the corners of the outer box. With a suitable electric current passing through the wire, the temperature of the water in the bath could either be kept constant or increasing at a desireu rate within a range from $1^{\circ}$ to $15^{\circ}$ above the temperature of the room. 'The whole of the interior of the bath; also the frame, and wire were coated with white paint. A tank of water of this kind containing over 40 litres cannot with any reasonable amount of stirring be kept at a sufficiently uniform temperature. The bulbs of the thermometers were therefore placed into a small copper box $B$, within which the stirring was much more efficient. The box was 15 centim. in breadth and 10 centim. deep, and was rigidly suspended from a wooden cross-bar resting on the side of the case. Vertically down the centre of the box passed a spipdle carrying a double 3-bladed screw-paddle; one of these paddles was fixed just below the bottom of the box, and the other just inside the box, as shown in the figure. There was a further paddle at the other end of the bath, the power being supplied by two Cuttriss motors. The stirring was sufficient to secure a very approximately uniform temperature all over the bath. The box $B$ sheltered the thermometers from outside radiation, and protected them against jets of hot water coming from the heated water, the paddle below the box being specially intended to prevent irregular heating of the box. The water inside B was thoroughly stirred, a mere rotation of the water being prevented by oblique diaphragms fixed to the sides. One further precaution was found advisable. Owing to evaporation and radiation the water lost heat at its upper surface, and the thermometers had to be protected against an inflow of cold water through the opening through which the spindle passed. This was done by a horizontal disk $\mathrm{H}$ fixed to the spindle, and by covering the whole box as far as possible with asbestos. The thermometer bulbs passed through a window $W \quad 3 \cdot 2$ centim. wide, cut into one side of $B$, and a sliding shutter of 
Fig. 4 .

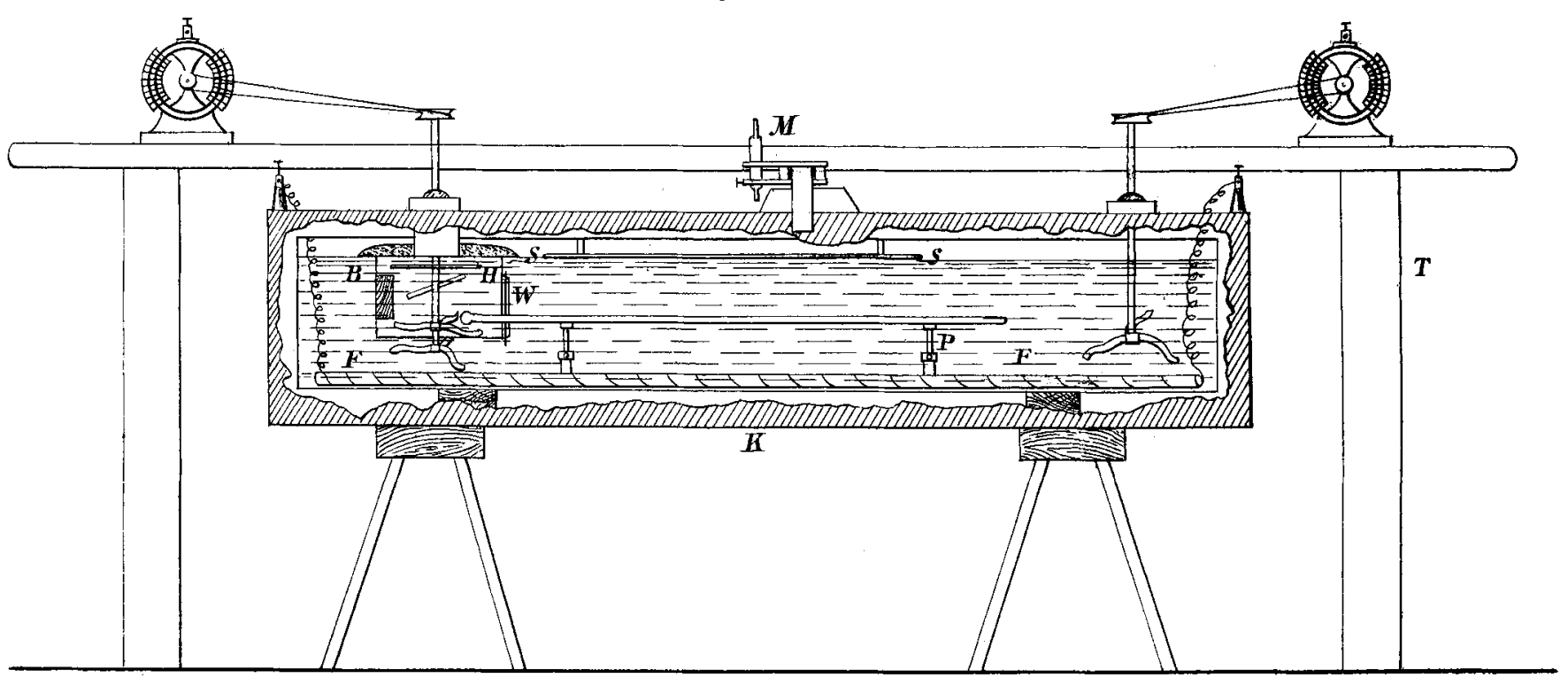

Mintern Bros. Jith 
thin brass served to close the window partially so that there was only very little, if any, circulation of water between the inside and the outside of the box.

The thermometers were read by a small microscope $M$ which could be moved parallel to itself along the upper edges of the outer vessel. The microscope was mounted so that it also had a free motion at right angles to the length of the box. This double motion allowed it to be mored quickly above the ends of the threads of any two thermometers to be compared. Latterly two microscopes were used, one for each of the thermometers. 'The water was covered by a sheet of glass, which kept the surface calm in spite of the disturbance set up by the stirring. The thermometers were supported in triangular grooves cut into two adjustable brass uprights $\mathrm{P}, \mathrm{P}$. Care was always taken to set them horizontally by first placing a straight edge across the uprights and levelling. This horizontal position is not necessary when the thermometers are transparent, so that their divisions can be read either from the front or from the back, as errors of parallax are thus eliminated. But when this cannot be done the reading microscope must be placed at right angles to the thermometer, and then it is most convenient to have one vertical and the other horizontal. The optic axis of M was put into the vertical position by keeping at a proper distance in the bath a horizontal glass-scale silvered at the back. When the adjustment is correct the two images of the division which is in the centre of the field of view should cover each other, otherwise there is parallax. As the object of the adjustment is to aroid parallax in the reading of the thermometers, this method answers very well if the glass-seale is about 2 millim thick. It is instructive to notice how great the danger of error due to parallax is when sufficient care is not taken to read only in the centre of the field of view.

\section{The Method of Comparison and Reduction.}

Two observers were found necessary to carry out a satisfactory comparison, one calling out the time at regular intervals and taking the notes, the other reading the thermometer. An example will show the method adopted.

On June 20, 1893, a comparison was made between Joule A and a Tonnelot Standard No. 4929. Both thermometers were kept in the bath at a temperature of $18^{\circ}$ for several hours, then their freezing-point was determined and found as follows :-

Tonnelot, No. 4929 : 0.0082 (mean of 4 observations). Joule A $: 23 \cdot 23$ 
The air of the room was above that of the bath, the temperature of which was slowly rising without the use of an electric current. The thermometers being replaced in the bath, readings were taken alternately every quarter minute, first with the divisions in front of the thread, and finally with the divisions behind. The numbers obtained were as follows:-

Tonnelot.

(Divisions in front.)

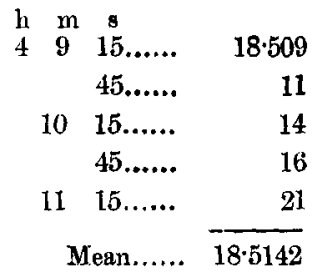

(Divisions behind.)

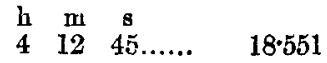

$$
\begin{aligned}
& 13 \quad 15 \ldots . . . \quad 53 \\
& 45 . . . . .61 \\
& 14 \quad 15 \ldots . . . \quad 72 \\
& 45 . . . . .74 \\
& \text { Mean ..... } \overline{18 \cdot 5622}
\end{aligned}
$$

General Mean 18.5382
Joule.

(Divisions in front.)

$$
\begin{array}{rrrr}
\mathrm{h} & \mathrm{m} & \mathrm{s} & \\
4 & \mathbf{9} & 30 \ldots . . & 458 \cdot 61 \\
10 & 0 \ldots . . . & 63 \\
10 & 30 \ldots . . & \cdot 66 \\
11 & 0 . . . . & .69 \\
& & & \\
& & & -\frac{6}{458 \cdot 648}
\end{array}
$$

(Divisions behind.)

$$
\begin{aligned}
& \begin{array}{llll}
\text { h } & \mathrm{m} & \mathrm{s} & \\
4 & 13 & 0 \ldots . . . & 459.06
\end{array} \\
& 1330 \ldots . . .16 \\
& 14 \quad 0 \ldots \ldots . \quad 39 \\
& 14 \quad 30 \ldots . . .48
\end{aligned}
$$

$$
\begin{array}{rrr}
\text { Mean } & \ldots . . & \overline{459 \cdot 273} \\
\text { General Mean } & . . . . & 458.961
\end{array}
$$

The zeros were now again determined and found :-

$$
\begin{array}{lcc}
\text { Tonnelot } & 0.0075 \\
\text { Joule A } & 23 \cdot 192(\text { mean of } 4 \text { observations). }
\end{array}
$$

A small correction is applied to the Joule thermometer for the lagging behind, and we thus got for corresponding temperatures:-

$$
\begin{array}{lrrr}
\text { Tonnelot } & 18.538 & \text { Joule } & 458.99 \\
\text { Zero . } & .008 & & 23 \cdot 21
\end{array}
$$

In the first series of comparisons the Joule A was compared in this way with the Tonnelot thermometer. The latter had been calibrated and investigated at the Bureau International des Poids et Mesures, so that its indications could at once be reduced to the normal scale. The results of the comparison are given in Table V. The first column gives 


\begin{tabular}{|c|c|c|}
\hline 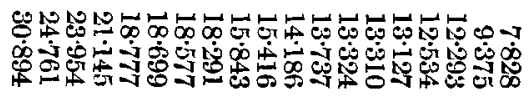 & $\stackrel{3}{3}$ & $\stackrel{-1}{ }$ \\
\hline 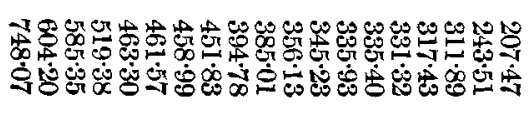 & $\begin{array}{c}\stackrel{c}{\circ} \\
\stackrel{5}{\circ} \\
P\end{array}$ & $F$ \\
\hline 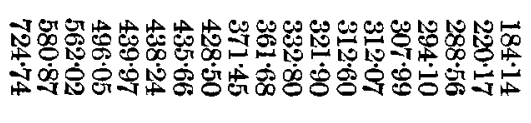 & 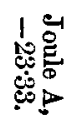 & F \\
\hline 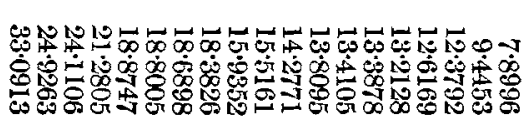 & 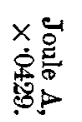 & 4 \\
\hline 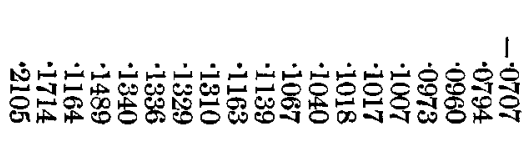 & 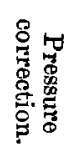 & .4 \\
\hline 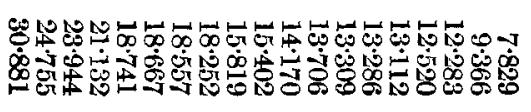 & $\because$ & $\not$ \\
\hline 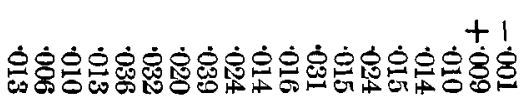 & 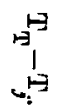 & $\vec{\Xi}$ \\
\hline 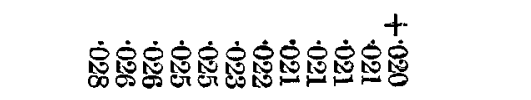 & $P$ & 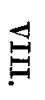 \\
\hline 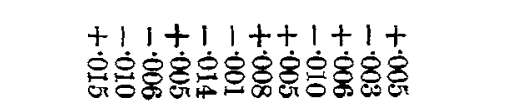 & 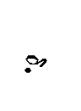 & : \\
\hline
\end{tabular}

Phil. Mag. S. 5. Vol. 39. No. 241. June 1895. $2 \mathrm{~L}$ 
the actual temperature on the French hard-glass mercury scale as determined by the Tonnelot. The second column gives the corresponding readings of "Joule A." As Joule, in his work, assumed a fixed zero of his thermometer, we must reduce the observations here also in the same way.

Any convenient position may be assumed as zero, as the scale-value which is to be deduced from the observations will only depend on the differences of readings, so that the zero is really eliminated. But it is convenient to take as zero that corresponding to the average temperature of the air, which in our case was about 23.33 . The third column gives, therefore, the numbers obtained by subtracting 23.33 from the readings given in the second column. If Joule's scale-value is correct these figures should, when multiplied by his factor, give the temperature as determined by a thermometer made of glass having the composition of these thermometers. Joule's reducing factor is 0.077214 , which for the Centigrade scale becomes -042897. For convenience of calculation I have taken it as 0429 . 'I'he fourth column gives the numbers so reduced. Columns V. and VI. give the corrections to the vertical position and the corrected readings. The last column gives the differences between the temperatures as deiermined by the Tonnelot and Joule's thermometer respectively. These numbers show no very marked increase or diminution between the temperatures of $10^{\circ}$ and $20^{\circ}$. If the numbers in column VI. were constant throughout, it would mean that the two thermometers read alike as regards differences of temperature.

In order to obtain the greatest possible information from the numbers obtained they were reduced by the method of least squares, all comparisons below $13^{\circ}$ and above $22^{\circ}$ being Jeft out of account as lying outside the range within which Joule worked. If $\mathrm{T}_{j}$ represents the reading on the Joule thermometer, $T_{T}$ that on the Tonnelot, and we wish to form an equation

$$
\mathrm{T}_{\mathrm{T}}-\mathrm{T}_{j}=a+b \mathrm{~T}_{\mathrm{T}}
$$

we may do so, substituting for $T_{T}-T_{j}$ the number in column $V I$., and for $\mathrm{T}_{\mathrm{T}}$ those in column $\mathrm{I}$. The constants $a$ and $b$ were, thus found to be

$$
a=0.0081, \quad b=0.000933 \pm \cdot 00068 .
$$

If we denote by $t_{\mathrm{T}}$ and $t_{j}$ intervals on the two thermometers we finally find

$$
t_{j}=t_{\mathrm{T}}(1-0 \cdot 00093)
$$


The result of this calculation, therefore, would be that the scale of the Joule thermometer is about one part in a thousand smaller than that of the Tonnelot, the difference being due either to a difference in the glass or to faulty calibration.

In order to compare the observed differences in the readings of the two thermometers with the values calculated from the most probable scale-value of the Joule, I have added columns VIII. and IX., the former giving the calculated value of $\mathrm{T}_{\mathrm{T}}-\mathrm{T}_{j}$, and the latter the difference $\delta$ which is either due to errors of observation or to irregular errors of graduation of one or other of the thermometers. Although the obvious fault in this respect shown by the Joule prepares us for occasional differences of about $0^{\circ} \cdot 01$, I was not, for several reasons, satisfied with the results of this series of comparisons. The apparatus had not reached its final form during these experiments, the stirring was not as good, and the thermometer had not yet been protected against the inflow of cold water through the opening in the roof of the inner box. A great difficulty was also found in comparing together directly the Joule.thermometer, which was rather sluggish in its motion, with the Tonnelot, which answered very quickly the smallest change of temperature. Unless care was taken, therefore, to make the rise exceedingly uniform errors were easily made. Additional uncertainty was introduced by the frequent redeterminations of the zero of the Tonnelot. The probable error of the calculated coefficient was too great to allow me to be satisfied with its value.

A second series of experiments was therefore decided upon, and as in a joint research in the equivalent of heat I had occasion, together with Mr. Gamnon, to determine with considerable accuracy the scale-value of a Baudin thermometer graduated directly to a 50th of a degree, I made use of the latter in the second series.

The experiments were made exactly in the same way as before, the Joule being directly compared with the Baudin, and zero readings being dispensed with. The results are embodied in Table VI. The first column gives the temperatures according to the Joule thermometer, the coefficient -0429 being again used, and the readings being converted to the vertical position. The second column gives the reading according to the Baudin thermometer, after the proper calibration correction had been applied and the reading also reduced to the vertical position. The third column gives the difference between the numbers in the two first.

\section{L 2}


TABLE VI.

\begin{tabular}{|c|c|c|c|c|}
\hline $\begin{array}{l}\mathbf{I} . \\
\mathbf{T}_{j}\end{array}$ & $\begin{array}{l}\text { II. } \\
\mathbf{T}_{\mathbf{B}^{*}}\end{array}$ & $\begin{array}{c}\text { III. } \\
\underset{\mathrm{B}}{\mathrm{P}}-\mathrm{T}_{j} \\
\text { observed. }\end{array}$ & $\begin{array}{c}\text { IV. } \\
\mathrm{T}_{\mathrm{B}}-\mathrm{T}_{j} \\
\text { calculated. }\end{array}$ & $\begin{array}{l}\text { V. } \\
\delta .\end{array}$ \\
\hline $\begin{array}{l}13 \cdot 9339 \\
14 \cdot 2114 \\
14 \cdot 4258 \\
14 \cdot 6885 \\
14 \cdot 9996 \\
15 \cdot 3201 \\
15 \cdot 7703 \\
16 \cdot 1221 \\
16 \cdot 5334 \\
16 \cdot 9247 \\
17 \cdot 2941 \\
17 \cdot 4847 \\
17 \cdot 7256 \\
18 \cdot 0034 \\
18 \cdot 2883 \\
18 \cdot 5526 \\
18 \cdot 7501 \\
19 \cdot 0095 \\
19 \cdot 27.20 \\
19 \cdot 5116 \\
19 \cdot 7012 \\
19 \cdot 9254\end{array}$ & $\begin{array}{l}13 \cdot 945 \cdot 2 \\
14 \cdot 2206 \\
14 \cdot 4359 \\
14 \cdot 7005 \\
15 \cdot 0120 \\
15 \cdot 3348 \\
15 \cdot 7866 \\
16 \cdot 1399 \\
16 \cdot 5413 \\
16 \cdot 9383 \\
17 \cdot 3103 \\
17 \cdot 4981 \\
17 \cdot 7380 \\
18 \cdot 0170 \\
18 \cdot 3015 \\
18 \cdot 5795 \\
18 \cdot 7660 \\
19 \cdot 0186 \\
19 \cdot 2907 \\
19 \cdot 5318 \\
19 \cdot 7174 \\
19 \cdot 9427\end{array}$ & 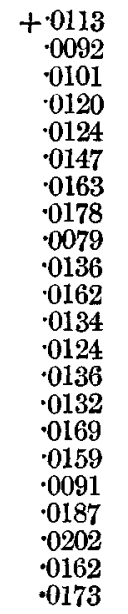 & $\begin{array}{r}+\cdot 0111 \\
\cdot 0113 \\
\cdot 0115 \\
\cdot 0118 \\
\cdot 0121 \\
\cdot 0124 \\
\cdot 0128 \\
\cdot 0131 \\
\cdot 0135 \\
\cdot 0138 \\
\cdot 0142 \\
\cdot 0143 \\
\cdot 0146 \\
\cdot 0148 \\
\cdot 0151 \\
\cdot 0153 \\
\cdot 0155 \\
\cdot 0157 \\
\cdot 0160 \\
\cdot 0162 \\
\cdot 0164 \\
\cdot 0166\end{array}$ & $\begin{array}{l}-\cdot 0002 \\
+\cdot 0021 \\
+\cdot 0014 \\
-\cdot 0002 \\
-\cdot 0003 \\
-\cdot 0023 \\
-\cdot 0035 \\
-\cdot 0047 \\
+\cdot 0056 \\
+\cdot 0002 \\
-\cdot 0020 \\
+\cdot 0009 \\
+\cdot 0022 \\
+\cdot 0012 \\
+\cdot 0019 \\
-\cdot 0016 \\
-\cdot 0004 \\
+\cdot 0066 \\
-\cdot 0027 \\
-\cdot 0040 \\
+\cdot 0002 \\
-\cdot 0007\end{array}$ \\
\hline
\end{tabular}

The figures of this table were reduced in the same way as those of the first series of measurements. If we write

$$
\mathrm{T}_{\mathrm{B}}-\mathrm{T}_{j}=a+b \mathrm{~T}_{\mathrm{B}}
$$

we find by the method of least squares

$$
\begin{aligned}
& a=-\cdot 0017, \\
& b=+\cdot 00092 \pm \cdot 00022 .
\end{aligned}
$$

The values of $\mathrm{T}_{\mathrm{B}}-\mathrm{T}_{j}$ calculated by this formula are entered into the fourth column of Table VI. The differences $\delta$ between the calculated and observed values, which are also given, are seen to be as small as can be expected, never rising to more than $0^{\circ} 006$. This series having yielded a satisfactory comparison, we must reduce the scale-values obtained by applying the scale-correction of the Baudin thermometer. Denoting the intervals as read off by the thermoneters by the small letter $t$, the above reductions give

$$
t_{j}=t_{\mathbf{B}}(1-\cdot 00092) \text {. }
$$

A small correction is necessitated by the fact that a slight 
error was discovered in the pressure-coefficient of the Baudin thermometer after all the above reductions had been made. The corrected interval equation becomes

$$
t_{j}=t_{\mathrm{B}}(1-\cdot 00084)
$$

The comparison between the Baudin and Tonnelot thermometers made by $\mathrm{Mr}$. Gannon and myself had given

$$
t_{\mathrm{T}}-t_{\mathrm{B}}=-\cdot 00089 t_{\mathrm{B}} \text {. }
$$

Hence, by combining the last two equations,

$$
t_{j}=t_{\mathrm{T}}(1+\cdot 00005) \text {. }
$$

This comparison would therefore show that the Joule and Tonnelot thermometers read exactly alike.

In all these measurements the Baudin and Joule were always read like calorimeter thermometers, without regard to the change of the freezing-point, while the Tonnelot was referred in every case to its proper zero. The equality of the scalevalue of the two thermometers does not hold when they are both read in the same way, but the same interval read on the Tonnelot would be about one part in a thousand smaller than if read on $A$.

We may combine the results of the two series of comparisons by giving each weights inversely proportional to the probable error of the quantity denoted by $b$.

We therefore find as the most probable value for $t_{j}$,

$$
t_{j}=t_{\mathrm{m}}(1-\cdot 00027) \text {. }
$$

Without attaching undue importance to this number, we may say that it represents the relation between the Tonnelot standard and Joule's thermometer as accurately as the divisions and calibration of the latter will allow us to judge. The number seems certainly not to be in error by more than one part in a thousand, and probably by less.

The transition to the nitrogen and hydrogen scale may now be made. Using Chappuis' experimental investigation on the French hard-glass thermometers, it is found that a temperature of $16^{\circ} .5$, to which Joule's last equivalent determination refers the interval on the Tonnelot thermometer, is to be diminished by $\cdot 00268$ or $\cdot 00305^{*}$, according as we want to obtain the interval on the nitrogen or hydrogen scale. Thus writing

$$
\text { we find } \quad \begin{aligned}
t_{\mathrm{N}} & =t_{\mathrm{T}}(1-\cdot 00268), \\
t_{\mathrm{H}} & =t_{\mathrm{T}}(1-\cdot 00305), \\
t_{j} & =t_{\mathrm{N}}(1+\cdot 0024), \\
t_{j} & =t_{\mathrm{H}}(1+\cdot 0028) .
\end{aligned}
$$

* See Schuster and Ganṇon, Proc. Roy. Soc. Ivu. p. 28 
There is a marked difference between the results of this investigation and that deduced by Rowland * from the comparison of Joule's thermometers with his Baudin No. 6166. Tables VII. (referring to the first of the above series of comparisons) and VIII. (to the second) are intended to bring out this difference.

The numbers entered into the different columns of TableVII. are as follows :-

Column I. $T_{T}$ or the reading on the Tonnelot thermometer.

,

II. $\mathrm{T}_{\mathrm{T}}-\mathrm{T}_{j}$ or the corresponding difference in the reading on the scale used by Joule and the Tonnelot scale.

,III. $\mathrm{T}_{\mathrm{N}}-\mathrm{T}_{\mathrm{T}}$, the correction to the Chappuis nitrogenscale as interpolated between the numbers given in the table at the end of Guillaume's Thermométrie.

IV. The calculated difference $\left(T_{j}-T_{N}\right)$ between the Joule and Chappuis nitrogen-scale.

"V. The corresponding difference $\left(\mathrm{T}_{j}-\mathrm{T}_{\mathrm{N}}\right)_{\mathrm{R}}$ between the Joule and Rowland's air-thermometers.

"VI. The difference $\delta$ between the numbers given in Columns IV. and V.

A word of explanation is necessary as to how the numbers of Column V. have been obtained. Rowland gives in his paper the difference in the readings between Joule A and what he calls the "perfect" air-thermometer at a great number of points, none of them corresponding of course exactly to those of Column I., for which they are here required. I have taken the average between the value given for the temperature which lies nearest to that of Column I. and the two which lie immediately above and below it. The figures alter sufficiently slowly and with sufficient regularity to allow us to consider the numbers thus found as substantially correct.

We may deal more simply with the numbers obtained in the second series. The comparison between the Tonnelot and the Baudin thermometer already referred to gave, for the connexion between the two, the equation

$$
\mathrm{T}_{\mathrm{T}}-\mathrm{T}_{\mathrm{B}}=\cdot 0194-\cdot 00089 \mathrm{~T}_{\mathrm{B}}
$$

Combining with this the experimental connexion between the Joule and Baudin,

$$
\begin{aligned}
& \mathrm{T}_{\mathrm{B}}-\mathrm{T}_{j}=-.0017+\cdot 00084 \mathrm{~T}_{\mathrm{B}}, \\
& \mathrm{T}_{\mathrm{T}}-\mathrm{T}_{j}=\cdot 0177-.00005 \mathrm{~T}_{\mathrm{T}} ; \\
& \text { * Proc. Amer. Acad. xvi. p. } 38
\end{aligned}
$$


and from this we may calculate for the temperatures lying between $14^{\circ}$ and $22^{\circ}$ the difference between the Tonnelot and Joule readings. These are entered in Column II. of Table VIII, the remaining columns have the same meaning as those in Table VII.

Table VII.

\begin{tabular}{|c|c|c|c|c|c|}
\hline $\begin{array}{c}\mathrm{I} \\
\mathrm{T}_{\mathrm{T}}\end{array}$ & $\begin{array}{c}\text { II. } \\
\mathrm{T}_{\mathrm{T}}-\mathrm{T}_{j^{*}}\end{array}$ & $\begin{array}{c}\text { III. } \\
\mathbf{T}_{\mathrm{N}}-\mathrm{T}_{\mathbf{T}^{*}}\end{array}$ & $\begin{array}{c}\mathrm{IV} \\
\mathrm{T}_{j}-\mathrm{T}_{\mathrm{N}}\end{array}$ & $\begin{array}{c}\mathrm{V} . \\
\left(\mathrm{T}_{j}-\mathrm{T}_{\mathrm{N}}\right)_{\mathrm{R}}\end{array}$ & $\begin{array}{c}\text { VI. } \\
\delta .\end{array}$ \\
\hline $7 \cdot 828$ & -001 & -037 & 098 & .052 & 014 \\
\hline $9 \cdot 375$ & +009 & .043 & .034 & .058 & .024 \\
\hline $12-293$ & $\cdot 010$ & .054 & 044 & .077 & .033 \\
\hline $12-534$ & 014 & .055 & .041 & 079 & .038 \\
\hline $13 \cdot 127$ & 015 & .056 & 041 & 080 & $\cdot 039$ \\
\hline $13-310$ & .024 & $\cdot 057$ & $\cdot 033$ & .083 & 050 \\
\hline $13 \cdot 324$ & 015 & .057 & .042 & $\cdot 083$ & 041 \\
\hline 13737 & 031 & .058 & .027 & .085 & 058 \\
\hline $14-186$ & 016 & .059 & .043 & .085 & .042 \\
\hline $15-416$ & .014 & .063 & .048 & .094 & .045 \\
\hline 15843 & $\cdot 024$ & .064 & .040 & $\cdot 084$ & .054 \\
\hline 18.291 & $\cdot 039$ & $\cdot 069$ & $\cdot 030$ & ·104 & .074 \\
\hline 18.577 & .020 & .072 & -052 & $\cdot 104$ & 052 \\
\hline 18699 & $\cdot 032$ & .072 & .040 & $\cdot 104$ & $\cdot 064$ \\
\hline 18777 & $\cdot 036$ & $\cdot 070$ & .064 & $\cdot 104$ & $\cdot 040$ \\
\hline $21 \cdot 145$ & $\cdot 013$ & 077 & .064 & $\cdot 108$ & .044 \\
\hline 23954 & $\cdot 010$ & .083 & $\cdot 073$ & $\cdot 112$ & $\cdot 045$ \\
\hline $24 \cdot 761$ & $\cdot 006$ & $\cdot 084$ & $\cdot 078$ & $\cdot 116$ & $\cdot 038$ \\
\hline 30.894 & $\cdot 013$ & $\cdot 092$ & .079 & & \\
\hline
\end{tabular}

Table VIII.

\begin{tabular}{|c|c|c|c|c|c|}
\hline $\begin{array}{l}\mathrm{I} . \\
\mathrm{T}_{\mathrm{T}} \cdot\end{array}$ & $\begin{array}{c}\text { II. } \\
\mathrm{T}_{\mathbf{T}}-\mathrm{T}_{j}\end{array}$ & $\begin{array}{c}\text { III. } \\
\mathrm{T}_{\mathrm{N}}-\mathrm{T}_{\mathrm{T}} .\end{array}$ & $\begin{array}{c}\mathrm{IV} . \\
\mathrm{T}_{j}-\mathrm{T}_{\mathrm{N}}\end{array}$ & $\begin{array}{c}\nabla \\
\left(\mathrm{T}_{j}^{i}-\mathrm{T}_{\mathrm{N}}\right)_{\mathrm{R}}\end{array}$ & $\begin{array}{l}\text { VI. } \\
\delta .\end{array}$ \\
\hline $\begin{array}{l}18 \\
14 \\
16 \\
18 \\
20 \\
22\end{array}$ & $\begin{array}{r}+.0171 \\
.0170 \\
\cdot 0169 \\
\cdot 0168 \\
\cdot 0167 \\
\cdot 0166\end{array}$ & $\begin{array}{l}-.053 \\
-.059 \\
-.065 \\
-.070 \\
-.075 \\
-.079\end{array}$ & $\begin{array}{l}.036 \\
.042 \\
.048 \\
.054 \\
.058 \\
.062\end{array}$ & $\begin{array}{l}.077 \\
.085 \\
.094 \\
.101 \\
.109 \\
\cdot 110\end{array}$ & $\begin{array}{l}\cdot 041 \\
.043 \\
\cdot 046 \\
.047 \\
.051 \\
.048\end{array}$ \\
\hline
\end{tabular}

The two series of measurements agree in showing a difference of nearly $0^{\circ} .05$, which must be either due to a real difference between Rowland's "perfect" air-thermometer and that of Chappuis, or to some error in one or other of the comparisons.

We have no information at all as to how Joule proceeded in comparing together his thermometer with that of Rowland. The numbers furnished by Joule are obviously not those 
obtained directly by experiment, as they are given to the thousandth part of a division. Joule probably only gave the mean between a certain number of successive observations ranging over several divisions of his scale. He would in this way eliminate the errors of division, and the regularity in the difference between bis and Rowland's thermometer shows that some such process must have been adopted. There are certain corrections also no doubt applied by Joule, such as that due to the emergent stem, about which it would be necessary to have further information, before any definite conclusions can be drawn.

The important question as to a possible difference in the air-thermometers of Rowland and Chappuis can only be set at rest by a direct comparison of one of Rowland's thermometers with one compared at the Bureau International des Poids et Mesures.

But as regards the main point of the present investigation, this question does not arise. We are only concerned with Joule's thermometer, and the comparison between it and the Paris standard.

The relation between the intervals obtained by combining the two series of comparison was found to be, in terms of the Tonnelot nitrogen and hydrogen scales,

$$
\begin{aligned}
t_{j} & =t_{\mathrm{T}}(1-\cdot 00027) \\
& =t_{\mathrm{I}}(1+\cdot 0024) \\
& =t_{\mathrm{H}}(1+\cdot 0028) .
\end{aligned}
$$

Joule's final value for the equivalent of heat therefore reduces as follows :-

Joule's value for a temperature $61^{\circ} \cdot 69 \mathrm{~F}$. $\left(16^{\circ} \cdot 5 \mathrm{C}\right.$.). $\quad 772 \cdot 65$ On the scale of the French hard-glass thermometer. $\quad \mathbf{7 7 2} \cdot 44$ On the scale of the nitrogen thermometer of the

Bureau International des Poids et Mesures . . 774.51 On the scale of the hydrogen thermometer of the Bureau International des Poids et Mesures . . 774.81

Rowland applies a small correction to Joule's value of the heat-capacity of his calorimeter. This would raise the equivalent by $\cdot 2$. Taking account of this, and considering that Joule's thermometer was never intended to measure temperatures nearer than one part in a thousand, and is not graduated sufficiently well to allow the decimal place to be determined with any certainty, we may state it as the result of this in restigation that

Joule's equivalent of heat resulting from his own investigations 
and reduced to the nitrogen thermometer of the Bureau International des Poids et Mesures is to the nearest unit 775 footpounds at the sea-level and the latitude of Greenwich. The number refers to a pound of water weighed in vacuo at a temperature of $61^{\circ} .7 \mathrm{~F} .\left(16^{\circ} .5 \mathrm{C}\right.$.).

The equivalent reduced to ergs becomes $4.173 \times 10^{-7}$.

It is not necessary to discuss the older observations of Joule, or to modify his numbers by attaching weights to his experiments different from those which he gave to them himself. The result of Joule's last paper, as reduced by himself, should be taken as his final judgment. Rowland's value at $16^{\circ} .5$ is $4 \cdot 186 \times 10^{7}$, but the results of this paper open out the possibility that this number might have to be reduced somewhat when referred to the Paris air-thermometer. It seems most probable that the correct value of the equivalent lies somewhere between Joule's value and that of Rowland. The higher values obtained by Mr. Griffiths and myself and Gannon by the electrical method are not easily accounted for, but for the present they cannot in my opinion be put into competition with the direct determinations of Joule and Rowland. The discrepancy no doubt will be cleared up. In the meantime a comparison between one of Rowland's thermometers and the Paris standard would be of great interest.

XLIX. On the Kinetic Energy of the Motion of Heat and the corresponding Dissipation Function. By Dr. LadisLas Natanson, Professor of Natural Pliilosophy, University of Cracow*.

1. T $\mathrm{N}$ the following the fundamental assumptions of the 1 former paper ("On the Kinetic Interpretation of the Dissipation Function") will be adopted. A fluid medium is considered which is supposed to consist of a multitude of moving molecules. Let $u, v, w$ be the components of the "molar" velocity, i.e. of the mean velocity of the molecules within an element $d x d y d z$; and let $\xi, \eta, \zeta$ be the components of the individual velocity of any given molecule in that element. We will employ the symbol $\rho$ to denote the density of the medium ; and $Q$ to denote any property of a molecule which depends on the values of $(u+\xi),(v+\eta)$, and $(w+\zeta)$. Let $\bar{Q}$ indicate the mean value of $Q$ for all molecules within

* Translated from "Rozprawy" (Transactions) of the Cracow Academy of Sciences, Math: and Phys. Section, rol. xxvii. Communicated by the Author. 